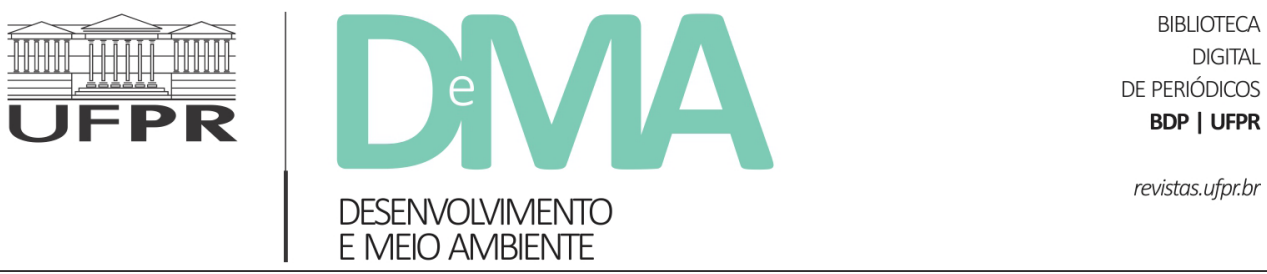

\title{
A apropriação do meio natural e a construção da paisagem urbana: análise dos impactos da implantação do Parque Ipiranga no bairro Jundiaí, em Anápolis (GO)
}

\section{The appropriation of the natural environment and the construction of the urban landscape: analysis of the impacts of the Ipiranga Park's implantation in the Jundiaí neighborhood, in Anápolis (GO)}

Ana Laura Lopes CABRAL ${ }^{1 *}$, Adriana Aparecida SILVA¹, Divina Aparecida Leonel LUNAS', Milena D’Ayala VALVA $^{1}$

${ }^{1}$ Universidade Estadual de Goiás (UEG), Anápolis, GO, Brasil.

*E-mail de contato: anarqurb20@gmail.com

Artigo recebido em 4 de outubro de 2019, versão final aceita em 13 de julho de 2020, publicado em 24 de novembro de 2020.

RESUMO: O trabalho problematiza a implantação do Parque Ipiranga no bairro Jundiaí, na cidade de Anápolis, analisando os impactos gerados na paisagem urbana desde 2010. Discutem-se os reais interesses dos agentes produtores do espaço urbano ao propor um parque ambiental, adotando como chave metodológica o levantamento do processo de verticalização no bairro, pelo qual foi possível observar sua recente expansão na região próxima ao parque. Outro fator relevante para a análise foi o uso de diversas mídias, especialmente as relacionadas às campanhas da administração municipal e anúncios imobiliários, que reforçam o discurso da qualidade de vida e valorização do bairro devido a presença do parque, fazendo com que haja maior atenção para o mesmo em detrimento dos demais parques da cidade. Conclui-se que ocorreu um processo de apropriação e valorização do espaço urbano pela iniciativa privada, apoiado pelo investimento público na implantação do Parque Ipiranga reforçando uma segregação socioespacial.

Palavras-chave: produção do espaço urbano; parque ambiental urbano; verticalização da paisagem.

ABSTRACT: The paper analyzed the implantation of Ipiranga Park in Jundiaí neighborhood in Anápolis, analyzing the impacts generated in the urban landscape since 2010. The real interests of the agents producing the urban space are discussed when proposing an environmental park, adopting as methodological key the survey of verticalization process in the neighborhood, through which it was possible to observe its recent expansion 
in the region near the park. Another relevant factor for analysis is the use of several media, especially those related to municipal administration campaigns and real estate announcements, which reinforce the quality of life's discourse and appreciation of the neighborhood due to the presence of the park, causing greater attention to even in detriment of other parks. It was concluded that a process of appropriation and valorization of urban space for the private initiative supported by the public investment in implantation of Ipiranga Park reinforcing socio-spatial segregation.

Keywords: urban space production; urban environmental park; landscape's verticalization.

\section{Introdução}

Inaugurado em 2010, o Parque Ipiranga é considerado o melhor parque de Anápolis, sendo referido, pelo próprio governo municipal, como o cartão postal da cidade (Anápolis, 2012). Levando em conta a sua localização no bairro Jundiaí que, desde sua criação em 1943, é reconhecido como um bairro nobre no contexto anapolino, nota-se que este tem passado por significativas alterações socioespaciais, especialmente na área do entorno imediato ao Parque.

Estas transformações são aliadas à valorização imobiliária consequente das novas dinâmicas que a abertura do parque tem ocasionado nesta área, o que compõe a principal hipótese do presente trabalho. As questões que se buscará responder nas discussões aqui apresentadas são: em que medida o meio natural é usado como instrumento do capital imobiliário e como ocorre esta interferência na configuração da paisagem urbana?

Adota-se aqui o conceito de paisagem que abrange os aspectos geográficos, nas dimensões tanto física como humana que se propõe discutir. Quanto a isso, Moreira \& Silva (2012, p. 3) afirmam que "O termo paisagem possui um significado mais amplo e complexo do que apenas o valor estético, referindo-se a tudo que a vista abarca, a ambientes construídos ou naturais, mas também é composta por elementos intangíveis e inclui valores e significados". Trata-se aqui, portanto, não somente de uma paisagem visual, mas de uma paisagem cultural, ou socialmente construída, conforme determinam as dinâmicas territoriais no âmbito urbano, que transformam as relações entre o ser humano e o seu meio.

Sobre o objeto de estudo, o Parque Ipiranga, sabe-se de antemão que existe uma estratégia ecológica (pelo menos inicialmente) com a sua implantação, no concernente à preservação do curso d'água ali existente, o córrego Ipiranga - cujas nascentes localizam-se no Clube Ipiranga ${ }^{1}$ - e de suas matas de galeria, a vegetação que compõe o ecossistema às suas margens, ainda composta por algumas espécies nativas do bioma Cerrado, e outras ali implantadas.

Mas, sabe-se também que a existência destas amenidades no meio urbano, como o lago, as áreas de preservação da vegetação, ou seja, o ambiente "natural" em sua totalidade, representa um atrativo para a fixação de pessoas em suas proximidades, principalmente por meio de empreendimentos imobiliários. Sobre isso, nos afirma Corrêa que

De fato, a ação dos promotores imobiliários se faz correlacionada a: (a) preço elevado da terra e alto status do bairro; (b) acessibilidade, eficiência e segurança

${ }^{1}$ Segundo Rocha (2007, p. 119), o clube foi fundado na década de 1950, tendo como primeiro presidente Dahas Bittar. O autor faz referência ao lugar como "um celeiro de revelação de atletas, principalmente em futebol e natação". Atualmente, encontra-se fechado para obras de futuro jardim botânico municipal. 
dos meios de transporte; (c) amenidades naturais ou socialmente produzidas; e (d) esgotamento dos terrenos para construção e condições físicas dos imóveis anteriormente produzidos, conforme indica R. S. de Almeida. Estas características em conjunto tendem a valorizar diferencialmente certas áreas da cidade, que se tornam alvo da ação maciça dos promotores imobiliários: são as áreas nobres, criadas e recriadas segundo os interesses dos promotores, que se valem de maciça propaganda. Assim, de um lado, verifica-se a manutenção de bairros de status, que continuam a ser atrativos ao capital imobiliário e, de outro, a criação de novas áreas nobres em razão do esgotamento de áreas disponíveis em outros setores valorizados do espaço urbano: os novos bairros nobres são efetivamente criados ou resultam da transformação da imagem de bairros antigos que, dispondo de alguns atrativos, tornam-se de status elevado (Corrêa, 1995, p. 23).

No caso do bairro Jundiaí, notam-se tanto a estratégia da manutenção de seu status, socialmente construído desde o planejamento, quanto uma tentativa de ressignificá-lo, revalorizando esta área da cidade. $\mathrm{O}$ acesso ao meio natural, tendo o parque urbano como o principal elemento, faz com que haja uma valorização do bairro e incremento de novas e velhas funções, quer sejam relacionadas com o residir, entreter-se ou mesmo investir.

Sabe-se que, em sua essência, os parques são ou deveriam ser espaços públicos. Sobre o conceito de espaço público, Serpa o compreende como "o espaço da ação política ou, ao menos, da possibilidade da ação política na contemporaneidade" (Serpa, 2007, p. 9). Conforme o autor, este espaço pode ainda ser analisado criticamente quando é incorporado como mercadoria para o consumo de poucos, e neste caso, "ainda que seja público, poucos se beneficiam desse espaço teoricamente comum a todos" (Serpa, 2007, p. 9).

$\mathrm{Na}$ tentativa de compreender melhor como se dão estes processos no locus da pesquisa, faz-se necessário contextualizar este objeto histórica e geograficamente, a partir de levantamento bibliográfico e da coleta de dados primários e secundários acerca do bairro onde o parque está inserido. No próximo item, tem-se a exposição destes dados para posteriormente analisar de forma pontual o Parque Ipiranga e seu entorno.

\section{O bairro Jundiaí: construção e reforço de sua imagem}

Pode-se afirmar, conforme Rocha (2007, p. 119), que o Clube Ipiranga foi o foco gerador da expansão urbana de Anápolis em direção à área hoje compreendida pelo bairro Jundiaí. Sabe-se que até a década de 1940, a cidade concentrava-se apenas numa margem do ribeirão das Antas, na região do centro tradicional, no entorno da matriz de Santana, a partir da qual originou-se o povoado (1860), depois elevado à Freguesia (1873), Vila (1887) e, finalmente, a Município, em 1907 (Batista, 2010).

Conforme entrevista publicada no jornal $O$ Anápolis em 16 de maio de 1943, concedida pelos dirigentes ${ }^{2}$ da Sociedade Imobiliária de Anápolis Ltda., criada neste mesmo ano, a iniciativa da implantação do bairro datava ainda de 1933, quando da construção do estádio do Anápolis Esporte Clube, na área hoje compreendida pelo Clube Ipiranga. Desde então, já aspiravam à construção de uma ponte sobre

\footnotetext{
${ }^{2}$ Lindolfo Louza, Jonas Duarte e Plácido de Campos, que, além de empreendedores imobiliários, eram ou vieram a ser gestores municipais e estaduais, em Anápolis e Goiás, respectivamente.
} 
o ribeirão das Antas para conectar a parte antiga da cidade ao estádio, facilitando o acesso ao mesmo, o que só ocorreu na década seguinte.

A primeira ação da Sociedade Imobiliária foi, então, a compra de terras na outra margem do ribeirão das Antas, pertencentes a fazendeiros, para demarcação do loteamento do bairro João d'Aí, que viria a ser Jundiaí. Contrataram a Companhia Serviços de Engenharia, de São Paulo, na pessoa de seu superintendente geral, dr. João Alves Toledo, engenheiro e urbanista encarregado do plano urbanístico (Figura 1). Este propôs um desenho que correspondia aos anseios modernistas da época, fazendo especial referência à cidade-jardim - conceituada no urbanismo por Ebenezer Howard - à medida que reservava boa porcentagem do solo urbano para espaços livres, verdes e de uso coletivo, além de largas ruas e avenidas, adequadas à circulação de um volume considerável de veículos (considerando a população da época).

A maioria destes espaços livres, no entanto, incluindo pequenos parques, praças, miolos de quadras destinados a feiras, ruas de serviço e outros, ainda na mesma década, não resistiram ao processo de apropriação do loteamento e sofreram privatização, dando lugar às novas construções e deixando de cumprir seu objetivo inicial.

De maneira geral, os espaços públicos que sobreviveram a este processo foram a Praça Dom Emanuel - ponto de convergência entre o bairro Jundiaí e o centro da cidade - e o corredor verde ao longo do curso do córrego Ipiranga, compreendendo desde o Clube Ipiranga à Praça Abadia Daher (Figura 2). Mesmo considerando essas perdas, vale ressaltar que a ideia inicial de uma região composta de incontáveis espaços verdes e públicos fez com que se criasse uma imagem de um bairro com boa qualidade de vida, informação que foi publicada nos jornais quando se referiam ao bairro como "O lugar mais saudável da cidade" e com vistas ao progresso urbano: "a nova Anápolis" (Figura 1).

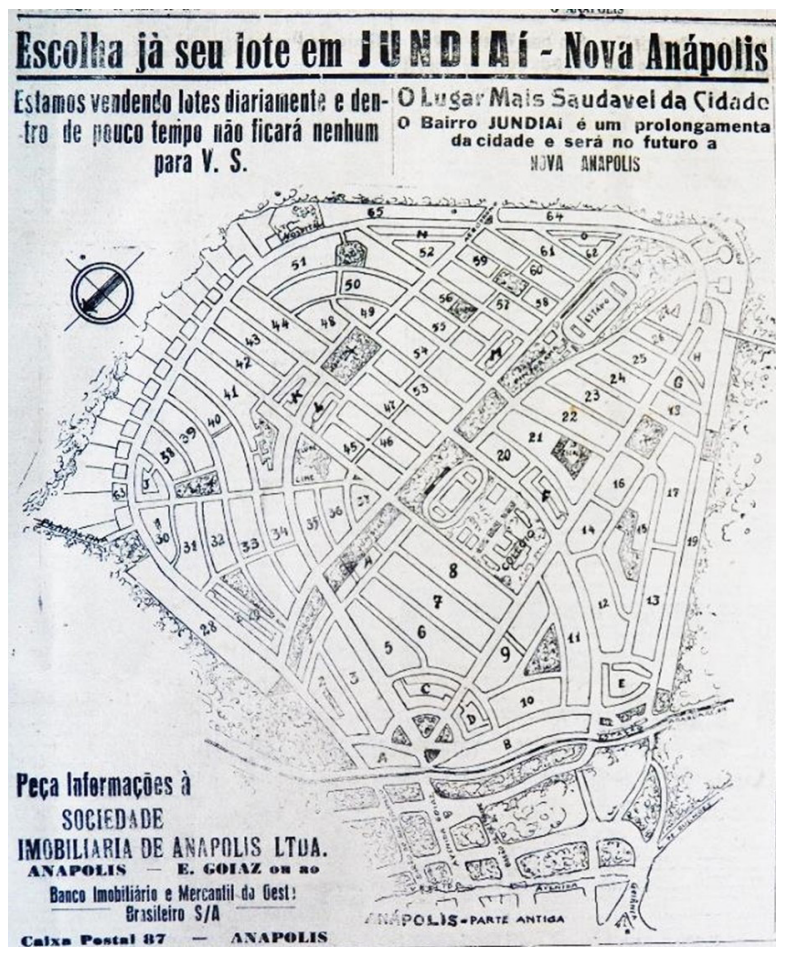

FIGURA 1 - Foto com o desenho urbanístico do bairro Jundiaí e outras informações, publicada no Jornal O Anápolis da década de 1940.

FONTE: registro da autora (2016) sobre acervo do Museu Histórico Alberico Borges de Carvalho.

Fábio Duarte afirma que "a vivência de um espaço se dá na relação entre o uso que se faz dele e a carga simbólica que lhe é impregnada", logo, se dá tanto na subjetividade como na dimensão do espaço construído, propriamente. "Estes elementos (objeto, uso, carga simbólica)", continua o autor, "alimentam-se e transformam-se constantemente; 
ou seja, tanto uma intervenção física pode alterar as possibilidades de uso de um espaço, quanto uma construção simbólica pode tentar induzir determinados usos" (Duarte, 2007, p. 194). O papel da publicidade estaria aliado a esta construção simbólica, com vias à indução de imagens e de usos.

Assim, pode-se dizer que, apesar da descaracterização do projeto original do bairro com a privatização da maioria dos espaços públicos planejados, essa imagem construída para o bairro se manteve e foi um dos fatores que contribuiram para que o Jundiaí fosse considerado como um bairro nobre e de status elevado.
“É necessário entender não apenas como os lugares adquirem qualidades materiais, mas também como adquirem valor simbólico através de atividades de representação" (Sánchez, 2001, p. 35), atividades estas que se dão por imagens e narrativas dos lugares, essencialmente veiculadas pelos meios de comunicação aliados aos agentes hegemônicos de produção e reprodução de espaços. Questiona-se a construção da própria imagem urbana, que, conforme Lucrécia Ferrara, é "uma representação construída cotidianamente pelos moradores, a partir da informação inferida da vivência de variáveis contextuais consideradas como elementos de informação urbana" (Ferrara, 1999, p. 71).

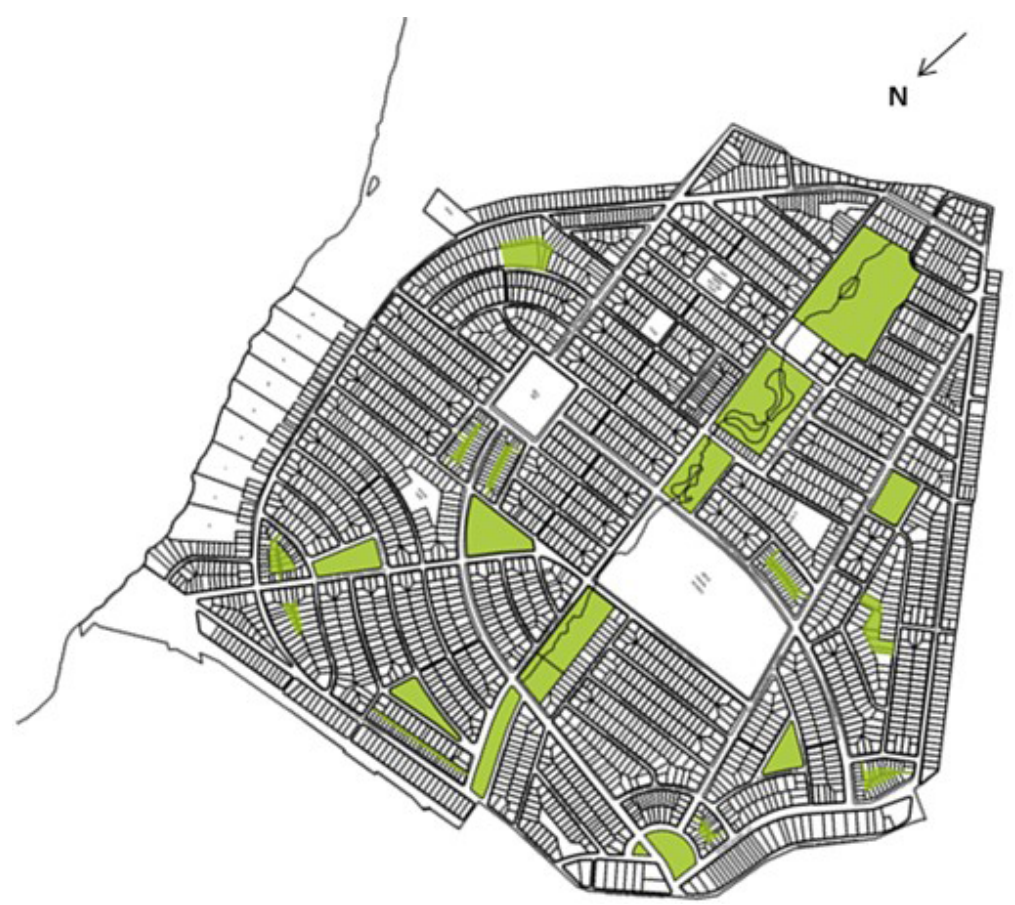

FIGURA 2 - Imagem com o desenho atual do Bairro Jundiaí destacando, em verde, os espaços livres planejados em 1943. FONTE: planta cadastral da Prefeitura de Anápolis (2016) alterado pela autora (2019). 
Em Anápolis, a partir da recente política ambiental, muito presente na última gestão municipal ${ }^{3}$, encontrou-se uma oportunidade de reforçar ainda mais a imagem do bairro Jundiaí, com a implantação do Parque Ipiranga, a partir da revitalização daquela área que já então se encontrava degradada. Diante disso, se buscará a seguir, explorar melhor o contexto que resultou na implantação do parque e o fenômeno da valorização do solo urbano decorrente desta intervenção urbana.

\section{A implantação do parque}

No corredor verde do córrego Ipiranga, entre o Clube, descrito anteriormente, onde se encontram suas nascentes, e o terreno da Paróquia São Francisco, cultivava-se a floricultura municipal, contornada por gradis e fechada ao público. Com o passar dos anos, a área, mesmo como propriedade do Clube endividado por não pagar seus impostos -, tornou-se depósito de lixo e até mesmo de vestígios criminais.

Depois de ocorrências e pedidos da população, a prefeitura decidiu intervir e, apossando-se do terreno devido à inadimplência do clube, anunciou em abril de 2009 a proposta de criação de um parque ambiental (Jornal Contexto, 2010). Tal iniciativa viria contribuir para a conservação do curso d'água e da vegetação de suas margens, além de devolver à população a área originalmente pública, que não estava cumprindo adequadamente sua função.

Em 2010, finalizadas as obras e entregue o parque, houve como consequência a revalorização daquela área do bairro, dado o acesso a este ambiente "natural", dotado de padrões e qualidades estéticas estabelecidos. Mas aqueles agentes para os quais a informação foi dada de forma privilegiadamente antecipada, adiantaram-se em investir nos arredores do futuro parque, adquirindo terrenos baratos (até então) e implantando novos empreendimentos.

Não demorou muito para que a dinâmica urbana fosse alterada, o que trouxe reflexos nem sempre positivos ou de acordo com os anseios coletivos. Além das intenções aparentemente boas, relativas à revitalização de áreas urbanas para abertura de parques ambientais, existem outras que atendem a interesses bastante específicos de determinados agentes produtores do espaço, como a promoção da gestão pública, a possibilidade de empreendimentos imobiliários apoiados ao conceito do parque, o desenvolvimento de atividades de negócios e prestação de serviços, etc. Quanto a isso, Serpa afirma que os novos parques

\begin{abstract}
Vêm alimentar e 'coroar' um processo de valorização imobiliária das áreas nobres da cidade, acrescentando novas amenidades físicas aos bairros que já possuem melhor infraestrutura de comércio e serviços, bem como vias expressas para circulação de veículos particulares (Serpa, 2007, p. 24).
\end{abstract}

Então, pode-se dizer que há um processo de "mercadificação" do serviço ambiental, na medida em que a ideia inerente à natureza está intimamente associada à qualidade de vida urbana e é posta à venda junto aos demais itens anunciados pelos programas residenciais. De acordo com Alves,

\footnotetext{
Desse modo, criam-se e valorizam-se espaços para moradia, lazer e turismo a partir da exploração da proximidade às áreas verdes e/ou aos parques contemplativos e às unidades de conservação ambiental,
}

\footnotetext{
${ }^{3}$ Nota-se que foi uma prioridade na gestão do prefeito Antônio Roberto Gomide, vinculado ao Partido dos Trabalhadores (PT). Seu primeiro mandato foi de 2009 a 2012, foi reeleito, mas renunciou em abril de 2014 para candidatar-se ao governo estadual (Anápolis, 2013).
} 
atribuindo à natureza a condição de mercadoria, junto à qual se vendem características de um ritmo de vida que tende ao desaparecimento na metrópole: a tranquilidade, o ar puro (agora um bem raro), a segurança e a beleza, todos postos em oposição à vida metropolitana (Alves, 2013, p. 119).

Tal apropriação é facilmente observada nos discursos de vendas dos novos empreendimentos dispostos no entorno do Parque Ipiranga e publicados nos anúncios de divulgação destes: "Exclusividade é morar em um condomínio vertical de alto padrão, com localização privilegiada e uma vista única para o parque mais bonito da cidade: O Parque Ipiranga." (PR, s.d.); "Viver próximo à natureza é o sonho de muitas famílias, mas ter um parque com mais de $45.000 \mathrm{~m}^{2}$ na porta de casa é um privilégio para poucos." (CE, s.d.); "Na Pinheiro Chagas, a 100 metros do Parque Ipiranga, um novo empreendimento vai se destacar na paisagem." (Opusic, s.d.).

Essa valorização intensifica, entre outros fatores, o processo de verticalização, com a construção de edifícios com cada vez mais pavimentos: o primeiro residencial com múltiplos pavimentos do Jundiaí, Privê Vilage Cardoso (entregue em 1988), possui quatro pavimentos, enquanto hoje tem-se, por exemplo, o Forma Opus Jundiaí, ainda em obras, que estima construir 26 pavimentos. Calculando a partir da Tabela 1, vemos que havia uma média de 11 pavimentos por edifício até o ano 2000, enquanto, de 2001 ao presente, essa média foi elevada a 19 pavimentos.

Além disso, os novos empreendimentos lançados parecem competir quanto ao padrão construtivo, ligeireza da execução e acabamento cada vez mais refinado, direcionando os imóveis à uma parcela bem específica da população, detentora de alto poder aquisitivo. Estes fenômenos já apresentavam sinais de sua ocorrência, ainda antes da entrega do parque, durante as obras, porque, como vimos, a própria população já previa as suas consequências.

\section{Repercussão na paisagem}

O processo de verticalização em Anápolis teve início na década de 1970, correspondendo ao que já se via também em várias outras cidades brasileiras: a construção de edifícios residenciais de múltiplos pavimentos. Este processo se intensificou na cidade especialmente a partir dos anos 1990, período em que se nota também o deslocamento deste fenômeno do centro pioneiro, onde se localizavam os primeiros prédios, para o bairro Jundiaí. Com a implantação do parque ambiental, há um salto ainda maior, tanto em número de empreendimentos como no de pavimentos. Conforme Rocha (2007),

Ao final do primeiro quinquênio do século XXI, quando se aproximava do seu centenário, celebrado em 2007, o crescimento de Anápolis adicionava um forte, talvez surpreendente mesmo, aumento de construção de edifícios residenciais. Antes em menor número de andares, agora acima de 10 andares (Rocha, 2007, p. 209).

Na Tabela 1, de autoria de Santos (2008), atualizada ${ }^{4}$ para fins desta pesquisa, é possível analisar o processo de verticalização no bairro Jundiaí, desde seu início ao tempo presente.

\footnotetext{
${ }^{4}$ Em sua monografia, Santos utilizou apenas os três primeiros intervalos de tempo, entre 1997 e 2008, quando seu trabalho foi concluído. A ideia agora é dar continuidade ao levantamento iniciado por ele, respeitando a escolha do intervalo temporal de quatro em quatro anos, acrescentando três novas colunas para chegar aos dias atuais.
} 
TABELA 1 - Empreendimentos verticais lançados entre 1997 e o presente no Bairro Jundiaí.

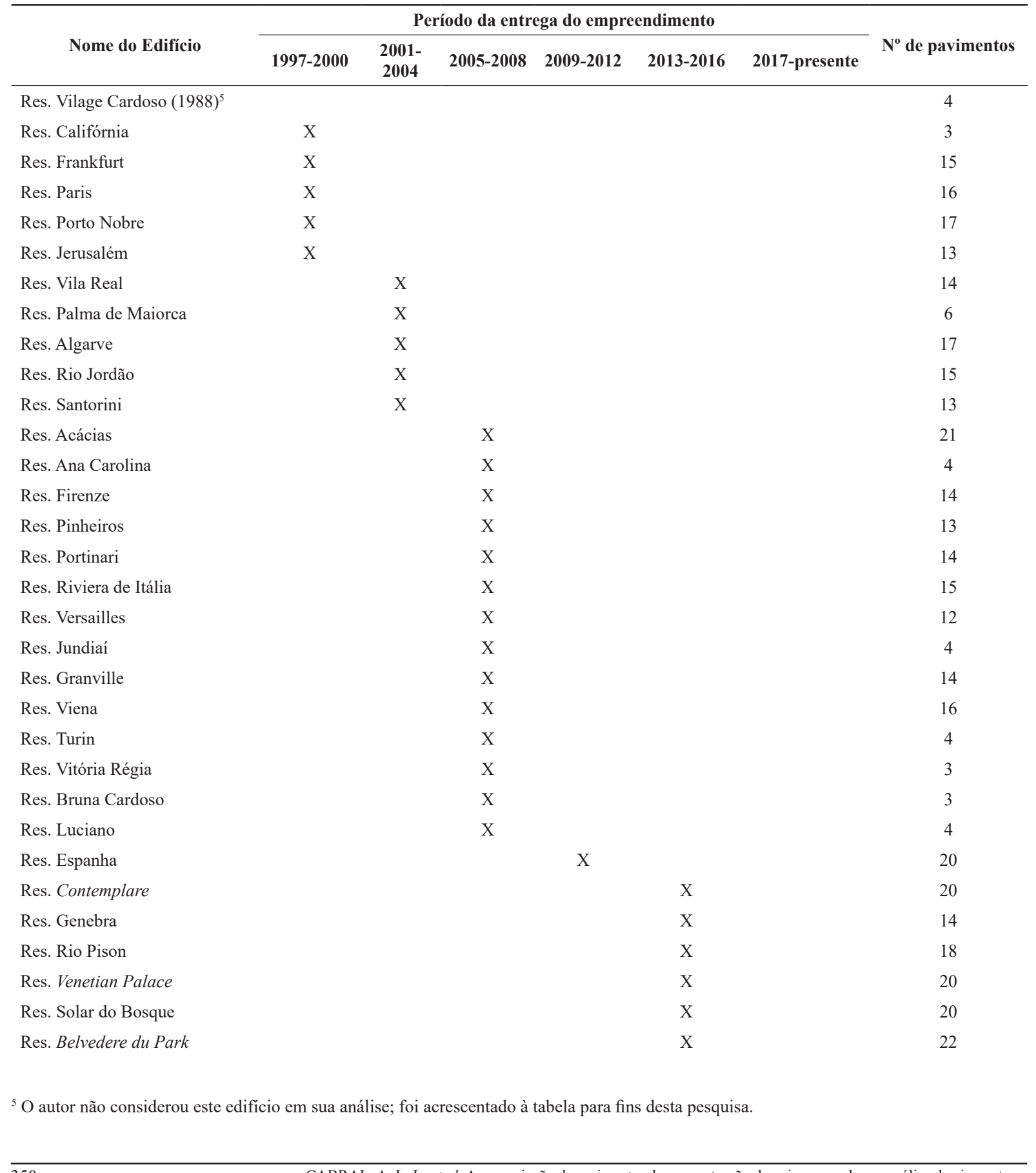




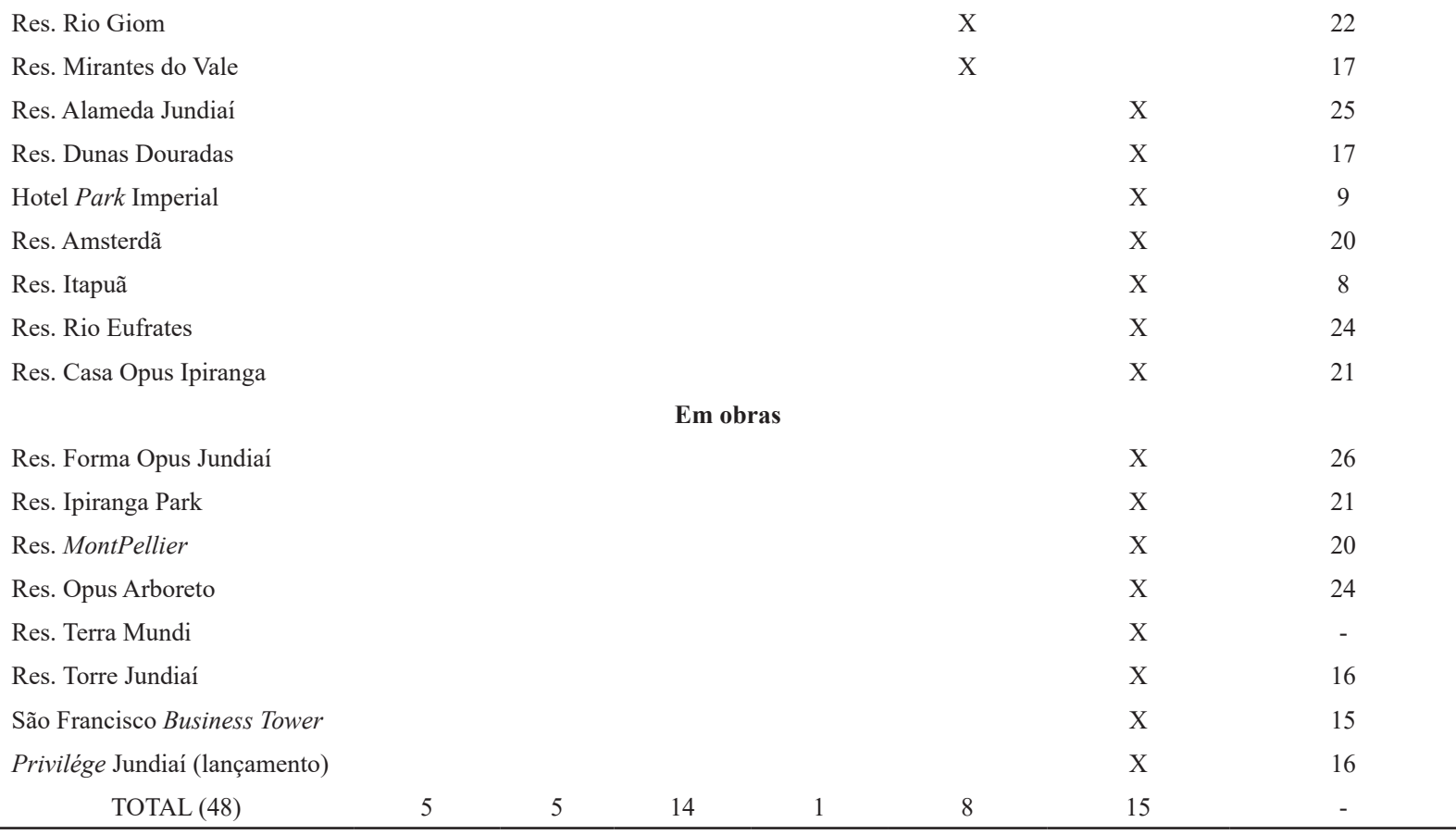

FONTE: Santos (2008), alterada pela autora (2019).

Na Figura 3 está representada a espacialização dos dados da Tabela 1, facilitando a análise dos processos aqui descritos, onde temos nos tons mais claros os empreendimentos mais antigos e, nos tons escuros, os empreendimentos mais recentes e, em verde, cortado por um canal de drenagem, a área do Parque.

Nota-se que nos empreendimentos iniciais, prevalecia uma tipologia de condomínios mais horizontais, com a implantação de blocos baixos, entre três e quatro pavimentos, dispersos em grandes terrenos. Essa tendência foi aos poucos se modificando, e o que se tem hoje, em grande parte, é a construção de um número menor de torres, mas estas com múltiplos pavimentos, em terrenos bem menores, portanto, com altos índices de ocupação e aproveitamento.

Grande parte destes novos empreendimentos, especialmente os que estão no entorno imediato ao Parque e ao Clube Ipiranga, apoiam seu marketing justamente nas vantagens de sua localização, que se apresenta como um privilégio aos investidores.

\section{Conforme Serpa,}

Elaborado e concebido como equipamento urbano na escala da cidade e da aglomeração, o parque público concretiza-se, em geral, no contexto de um grande programa imobiliário. Os discursos oficiais colocam sempre em primeiro plano as virtudes encarnadas por esse tipo de equipamento sem, no entanto, excluir seu valor econômico, menos sedutor do ponto de vista ideológico, mas determinante para a realização desse tipo de operação urbana (Serpa, 2007, p. 41). 


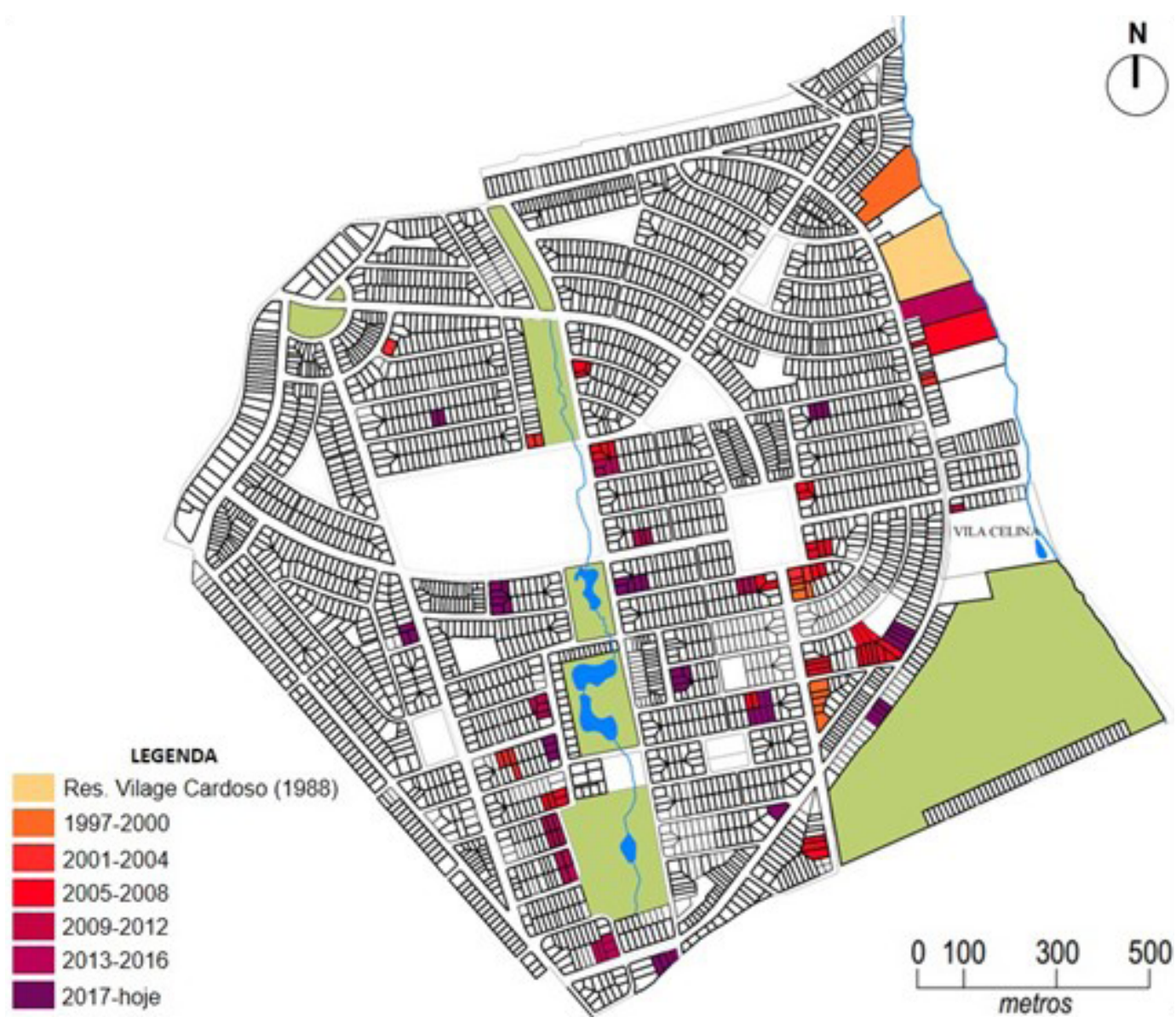

FIGURA 3 - Planta representativa do processo de verticalização do bairro Jundiaí, 1988 ao presente.

FONTE: planta cadastral da Prefeitura de Anápolis (2016) com intervenções da autora (2018).

A criação do parque e a busca pela valorização do bairro trouxe também a necessidade de instalação de novos equipamentos, que são utilizados para atrair compradores de imóveis, a exemplo do seguinte anúncio: “O imóvel está localizado no Jundiaí, bairro nobre da Cidade, próximo a escolas, clinicas, supermercado, lanchonetes e a poucos metros do Parque Ipiranga." (LC, s.d.). Assim, este processo de verticalização representa um adensa- mento populacional na região, acompanhada de outras transformações nas dinâmicas socioespaciais, como os fluxos de circulação de pessoas e veículos, além de mudanças de usos, visando fornecer estrutura física para estabelecimentos de comércio e prestação de serviços que atendam à demanda social emergente.

Fenômenos de crescimento urbano, como o adensamento, trazem consigo impactos de diver- 
sas naturezas, tanto ambientais como econômicos, sociais, de tráfego e tantos outros. Como exemplo de impacto ambiental, observa-se o problema do rebaixamento do lençol freático, que ocorre devido à implantação de obras em subsolos, destinados, em sua maioria, às áreas de estacionamento dos edifícios residenciais. Segundo publicado em setembro de 2014 pelo Jornal Contexto, "Dados da Secretaria Municipal de Obras, Serviços Urbanos e Habitação indicam que o nível do Córrego Ipiranga, nas proximidades do Parque Ipiranga, teve redução de até $50 \%$ em seu volume na nascente" (Jornal Contexto, 2014). A reportagem, que tem como subtítulo "Crescimento urbanístico sem controle seria a causa principal do esgotamento do leito", aponta que as construtoras dos novos empreendimentos estavam realizando a drenagem dos subsolos sem o posterior reabastecimento do lençol freático, gerando, paulatinamente, a redução do volume do curso d'água.

Vale lembrar que uma das diretrizes da Política de Qualificação Ambiental proposta no último Plano Diretor Participativo de Anápolis, apresentada no art. $146^{\circ}$, inciso VIII, diz: deve-se "restringir $o$ parcelamento do solo nas imediações, no entorno e adjacências das nascentes e dos cursos d'água" (Anápolis, 2016, p. 46). No entanto, o que se vê é o adensamento via verticalização das construções, as quais ocorrem, como registrado neste estudo, próximas às áreas de nascentes e vales de córregos.

Outra questão que se faz importante investigar é a respeito do licenciamento ambiental e dos estudos prévios para a realização de empreendimentos deste porte nas proximidades de cursos d'água, conforme propõe também o Plano Diretor da Cidade como um dos Institutos Jurídicos e Políticos da Política Urbana Municipal, no art. 196, inciso II: w) Estudo de Impacto Ambiental - EIA, Relatório de Impacto Ambiental - RIMA, Plano de Gestão Ambiental - PGA, Plano de Controle Ambiental PCA, Estudo Prévio de Impacto de Vizinhança - EIV, Estudo de Impacto de Trânsito - EIT e Relatório de Impacto de Trânsito - RIT (Anápolis, 2016, p. 66).

É interessante pontuar que não são apenas novas unidades residenciais, comerciais e de serviços que vêm alterando a paisagem do bairro. Existe a proposta de instalação de um Jardim Botânico no Clube Ipiranga, abarcando também a transferência das secretarias municipais de Educação, Saúde e Meio ambiente para o local (Portal 6, 2018). Estima-se que essa mudança será acompanhada do deslocamento de 800 servidores para a região diariamente, o que nos faz indagar sobre a dimensão dos impactos decorrentes destes novos fluxos para a dinâmica e o espaço urbano do bairro Jundiaí. Diante destes fatos, questiona-se ainda a aparente predileção do Parque Ipiranga em detrimento aos demais parques da cidade, buscando conhecer de forma mais ampla as circunstâncias que o favorecem em relação a estes outros.

\section{Construção do imaginário do melhor parque}

Como já mencionado neste estudo, a gestão municipal anterior em Anápolis foi caracterizada por consideráveis investimentos na política ambiental, especialmente a partir da criação de novos parques. Conforme Vainer et al.,

Assim como os grandes projetos tendem a promover rupturas na dinâmica imobiliária e na formação dos preços fundiários, as formas de envolvimento esta- 
tal na sua formulação, operação ou gestão também sofrem descontinuidade. A intervenção do Estado vai muito além de uma participação financeira e é decisiva ao produzir exceções ou renúncias fiscais ou urbanísticas que oferecem ao grande projeto um espaço legal formatado segundo suas necessidades (Vainer et al., 2012, p. 15)

A cidade de Anápolis conta com sete parques, os quais foram criados ao longo de sua história (Figura 4). Se compararmos a atenção recebida pelo Parque Ipiranga no cenário municipal, em vista dos outros parques nas demais áreas da cidade, percebemos que existe uma maior atenção a este. Tal fato se reflete em uma maior apropriação, esforços de manutenção, incentivo e promoção de atividades culturais, investimentos em infraestrutura, entre outros aspectos.

O primeiro parque criado em Anápolis foi no bairro Maracanã em 1985, o Parque Antônio Marmo de Canedo, chamado popularmente de Parque da Criança ou Parque da Matinha. Neste parque, localizado num bairro de predominância residencial

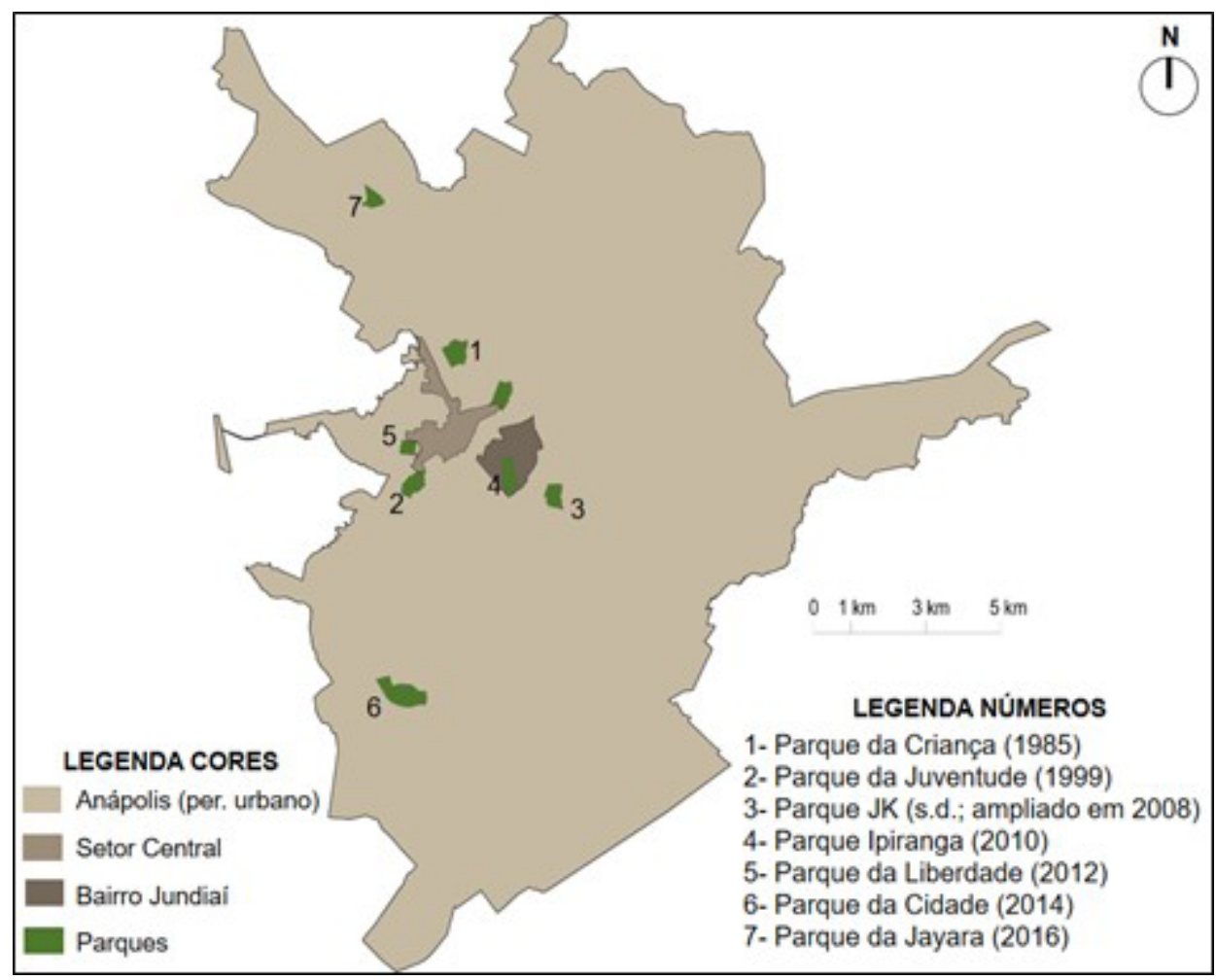

FIGURA 4 - Localização dos parques de Anápolis.

FONTE: planta cadastral da Prefeitura de Anápolis (2016) alterada pela autora (2019). 
a poucos quilômetros do centro pioneiro, é visível a despreocupação com a manutenção e atração de visitantes, uma vez que os brinquedos que compõem o parque de diversões encontram-se subutilizados (Figura 5). A área recebeu uma reforma em 2010, que incluiu a instalação de novos playgrounds e aparelhos de ginástica, mas os brinquedos originais permanecem em estado de abandono, deteriorados pela ação de intempéries e pelo vandalismo.

Na região central, no Parque Senador Onofre Quinan, ou Parque da Juventude, inaugurado em 1999 na Vila Góis, o lago para a preservação do Rio das Antas encontra-se assoreado. As obras de recuperação do canal foram iniciadas em 2012, com previsão de conclusão em 2015, o que não ocorreu, e o canal de drenagem segue degradado (Figura 6). A pista de caminhada ainda atende à sua função, servindo a determinado público e faixa etária, mas os equipamentos de playground estão abandonados, e outros foram removidos por falta de uso ou vandalismo, assim como no primeiro caso.

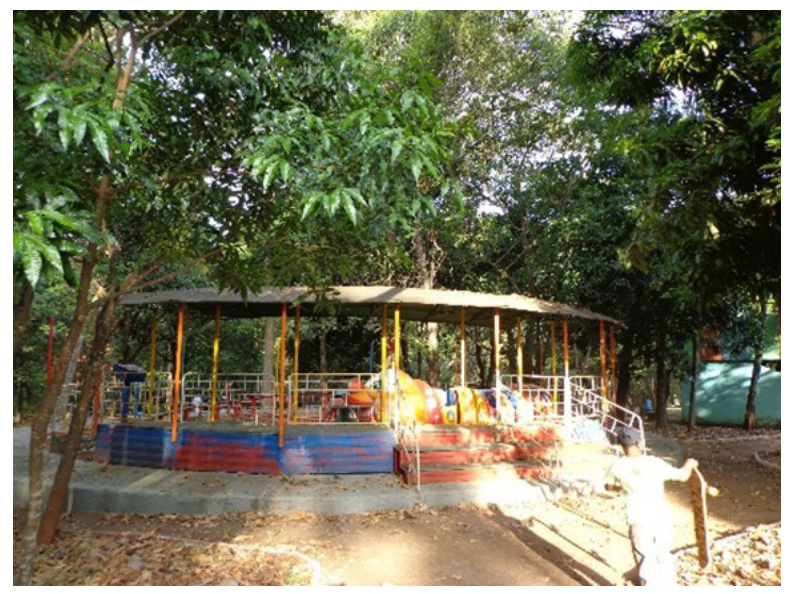

FIGURA 5 - Parque da Criança (brinquedo sucateado). FONTE: Registro da autora (2018).

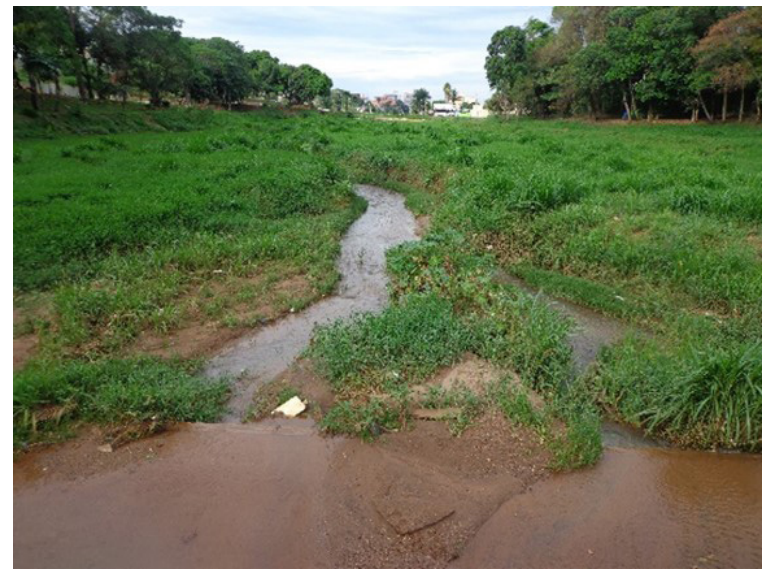

FIGURA 6 - Parque da Juventude (lago assoreado).

FONTE: Registro da autora (2018).

Já o Parque JK, localizado no bairro de mesmo nome, setor Nova Capital, o qual também é conhecido como "Praia", passou por obras de ampliação e de sinalização em 2008, e obras de controle de erosão em 2011, fazendo com que fosse mais bem aproveitado pela população. A pista de caminhada que contorna o lago por um bom tempo foi a melhor alternativa da cidade, mas atualmente é a rampa de skate que mais atrai jovens a frequentá-lo (Figura 7). Mesmo sendo um bairro afastado da área central, este parque conta com boa estrutura.

Considerando os parques criados mais recentemente, posteriores inclusive ao Parque Ipiranga, percebemos que eles não recebem a mesma atenção da gestão municipal ou não são considerados atrativos para os cidadãos. O Parque da Liberdade, por exemplo, datado de 2012, localiza-se no bairro São José, próximo à região central da cidade, e se refere à uma área de recuperação de uma antiga erosão que se tornara depósito de lixo, com a intenção de preservar as nascentes do córrego Catingueiro. Apesar 
de os caminhos estarem pavimentados, e de apresentar outros atrativos como lago, playground, estações de ginástica e locais de descanso, a topografia muito acidentada torna-o menos atrativo, fazendo com que uma pequena quantidade de pessoas o visite mesmo aos finais de semana (Figura 8).

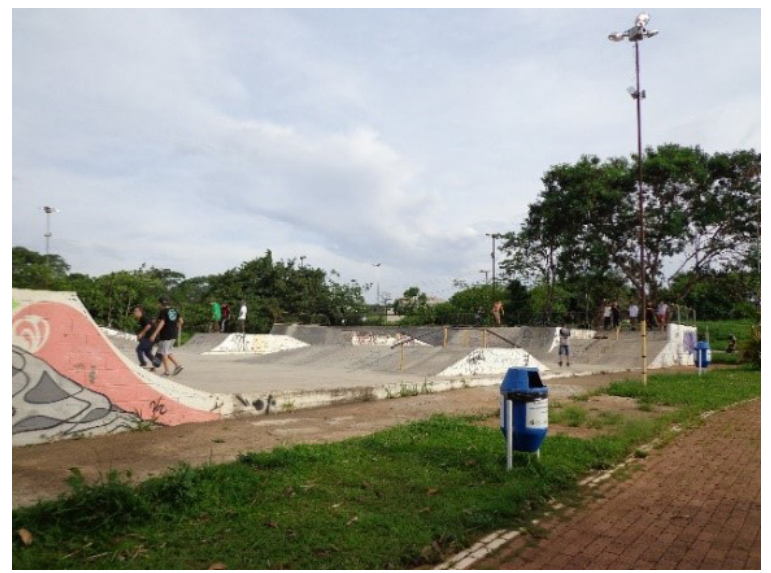

FIGURA 7 - Parque JK (jovens em pista de skate).

FONTE: Registro da autora (2018).

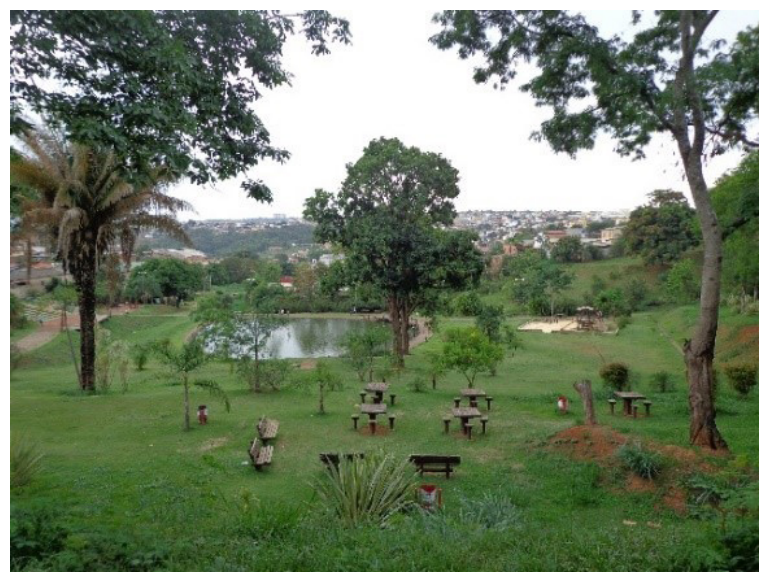

FIGURA 8 - Parque da Liberdade (vazio mesmo num domingo à tarde). FONTE: Registro da autora (2018).
O Parque da Cidade, ou Parque Ambiental das Antas, aberto em 2014, sendo fruto de uma compensação ambiental ${ }^{6}$ da Valec Engenharia, Construções e Ferrovias S.A., empresa vinculada ao Ministério dos Transportes, em decorrência das obras da Ferrovia Norte-Sul, localiza-se bem próximo às nascentes do ribeirão das Antas. A compensação ambiental responde ao que exige a Lei Orgânica vigente no município de Anápolis, em seu art. $200^{\circ}, \S 2^{\circ}$, que diz "Aqueles que exploram recursos minerais ficam obrigados a recuperar o meio ambiente degradado, de acordo com solução técnica exigida pelo órgão público competente, na forma da lei." (Anápolis, 2009, p. 59).

Conforme Carvalho et al. (2010, p. 6), “o projeto descreve que a qualidade ambiental do Rio das Antas está bastante comprometida na área de interferência da ferrovia com alguns bairros de Anápolis, nas proximidades do Kartódromo Internacional", daí a necessidade da criação do parque. Mas, como o mesmo localiza-se entre a rodovia BR-153 e o início da Avenida Brasil Sul, em uma área afastada dos grandes setores habitacionais, tal fato, provavelmente, justifica o abandono e a falta de apropriação pela população (Figura 9).

Por fim, o Parque da Jayara, inaugurado em 2016, foi o último a ser entregue pela administração municipal anterior. Trata-se também de intervenção em área degradada, uma vez que no local se instalou uma erosão, além disso, tratava-se de ponto de alagamento do córrego Reboleira. No final das obras, porém, sofreu danos devido a uma forte chuva, tendo que ser reformado e reentregue em 2018, já na gestão atual. Seus poucos frequentadores restringem-se aos moradores da Vila Jayara

${ }^{6}$ Uma espécie de indenização pela degradação, na qual os custos sociais e ambientais identificados no processo de licenciamento são incorporados aos custos globais do empreendedor (O Eco, 2015). 
e arredores, por tratar-se de uma área periférica da cidade, também à beira da rodovia Belém-Brasília (Figura 10).

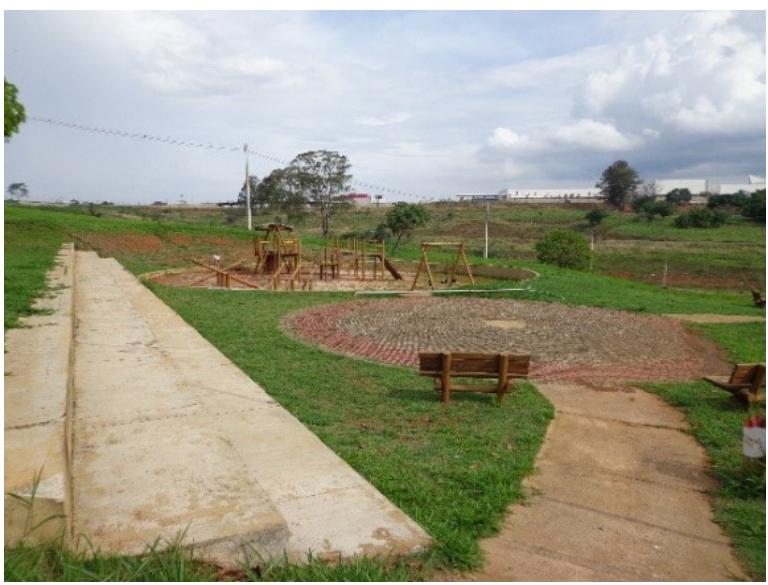

FIGURA 9 - Parque da Cidade (vazio mesmo num sábado à tarde). FONTE: Registro da autora (2018).

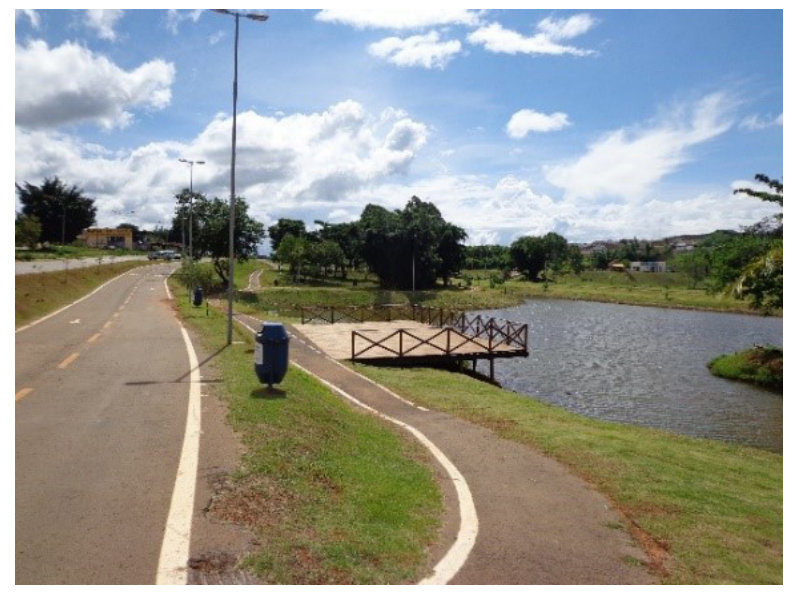

FIGURA 10 - Parque da Jayara (também pouco frequentado). FONTE: Registro da autora (2018).
Contrapondo-se a estes cenários, o Parque Ipiranga, desde que foi inaugurado em 2010, concentra notavelmente a atenção não só do poder público como do privado, a começar por localizar-se num bairro que desperta muito interesse destes agentes, e estando próximo ao centro tradicional, também se comporta como uma nova centralidade em Anápolis. Além disso, possui uma dinamicidade interessante, atraindo pessoas de diversas partes da cidade não só aos finais de semana, mas diariamente, e em diferentes períodos, inclusive à noite (Figuras 11 e 12).

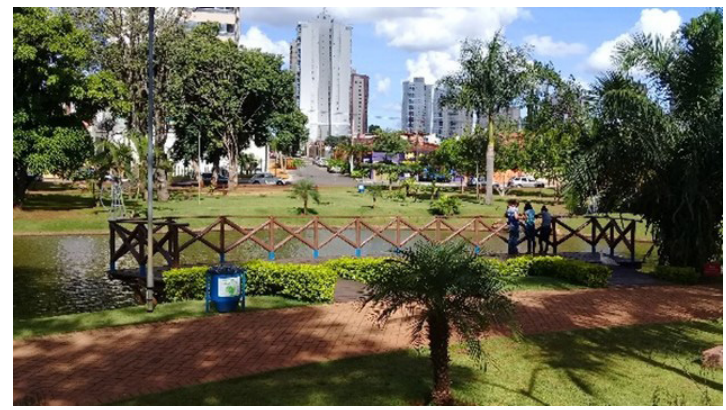

FIGURA 11 - Parque Ipiranga durante o dia.

FONTE: Registro da autora (2018).

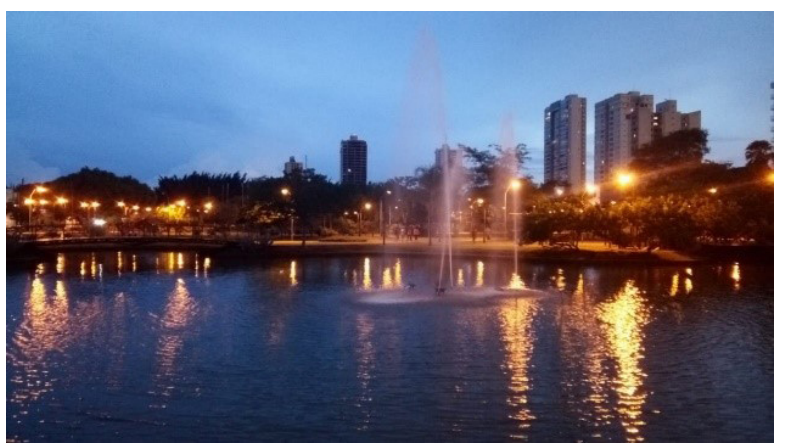

FIGURA 12 - Parque Ipiranga à noite.

FONTE: Registro da autora (2018). 
É recorrente encontrarmos afirmações nos diversos meios de comunicação referenciando-o como o local mais bonito e atrativo da cidade, como neste trecho de uma notícia publicada no portal da prefeitura, que dizia respeito ao parque da Liberdade, mas relembra a importância do Ipiranga: "Em dezembro de 2010 foi inaugurado o Parque Ambiental Ipiranga, no Bairro Jundiaí, que se tornou o mais novo cartão postal da cidade." (Anápolis, 2012). Esta é uma ideia que está sempre impregnada nos discursos de agentes públicos e imobiliários e volta e meia aparece, é defendida e reforçada como verdade.

Também a população absorve e replica esta imagem intencionalmente construída. Em entrevista com um administrador de um canal do YouTube, que faz filmagens do espaço urbano de Anápolis e de eventos e manifestações culturais da cidade, quando questionado sobre sua impressão acerca do Parque Ipiranga e dos demais parques da cidade, afirmou:

Acho que o comparativo é mais é a localidade, porque localidade igual essa aqui, não tem. E o povo gosta mais é daqui, não é verdade? Olha o Parque da Cidade: abandonado! Mas aqui colou por causa do bairro. Por isso que colou, se não tava abandonado também, igual lá. [...] Aqui não, aqui já vem gente de tudo quanto é lugar, né? (Filmagens, entrevista I, 2019).

Observa-se que o parque possui boa infraestrutura e recebe manutenção periódica, destacando-o em relação aos demais parques, sendo visíveis os serviços de iluminação, limpeza, segurança (inclusive monitoramento por câmeras) além de os equipamentos de playground e ginástica, que se encontram em bom estado de conservação. Desde julho de 2018, ele foi inserido no projeto Adote uma Praça, "que consiste em uma parceria público-privada para manutenção e revitalização desses espaços [públicos], a fim de trazer economia para o município e agilidade para esse tipo de processo" (Anápolis, 2018). De acordo com o site, o Parque Ipiranga foi então "adotado" pela Brainfarma Indústria Química e Farmacêutica $S / A$, que ficou responsável pela poda da vegetação, pintura e outros serviços.

Coletando falas da população sobre o processo de valorização do bairro, encontram-se impressões cujo registro é válido ao trabalho:

Olha foi de 1989 pra 1990 que começou a ter fama de nobre aqui, porque começaram a construir muita casa boa, mansão mesmo! Esse prédio aí mesmo [apontando], demoliram uma mansão pra fazer! As casinhas também tão virando tudo prédio. Eu tinha uns 6 anos, morava num barraco ali em frente o Ipiranga. Agora, só prédio. Depois de crescido fui morar em Salvador. Quando voltei pra cá, já tava bem diferente. Tinha uns conjuntinhos de casa ali, simples mesmo... Era dos funcionários das empresas que construía essas coisas ai. Hoje não constrói mais conjunto de casa assim aqui, constrói só longe; é na Jaiara, no Industrial... Mas não tem muito tempo que a coisa mudou não. Foi em 96 que trocaram os postes de madeira por esses de ferro aí. Se bem que ali perto da feira do Jundiai ainda tem uns postes de madeira! Não trocaram ali não. (Anônimo, entrevista II, 2020).

O entrevistado, habitante de outra área do bairro Jundiaí, concorda que o processo de verticalização envolveu uma mudança cultural e acredita que em breve as "casinhas simples" que ainda restam no entorno do parque logo irão ceder espaço para novos edifícios. 
Anápolis não tinha essa cultura de prédio, era só residência. Mas aí agora que tá tudo perigoso demais, começaram com moda de prédio, prédio... É bom pra gente, né? Mas pro Jundiaí não é não. A hora que acabar mais esse aí, [construindo na esquina] olha o tanto de apartamento, tudo com um, dois carros cada. E se todo mundo resolve sair de casa e voltar na mesma hora? Isso aqui para! Olha o que eu tô te falando, você pode escrever: daquele telhadinho pra lá [apontando para o rumo do parque Ipiranga], ainda tem muito barraquinho, feio, feio mesmo. Daqui 10 anos, não sobra mais nenhum, vira tudo prédio! (Anônimo, entrevista II, 2020).

\section{Considerações finais}

Conforme apresentado, as estratégias que envolvem a criação do Parque Ipiranga no bairro Jundiaí não se restringem à ideia inicial de recuperação de uma área degradada, com vistas à preservação do córrego existente e de suas matas. É possível perceber que as reais intenções vão além: dizem respeito a um conjunto de interesses públicos e privados no resgate ou reforço de uma imagem do bairro. Desde 1943, quando foi inaugurado como primeiro bairro formalmente planejado em Anápolis, o Jundiaí foi apresentado como o mais bonito, nobre, saudável, entre outros adjetivos.

Portanto, apesar de fazer parte de uma política ambiental que abarcou a implantação de diversos outros parques e praças na cidade de Anápolis, o Parque Ipiranga se sobressai em termos de investimentos públicos em manutenção, realização de atividades culturais, atração populacional e mesmo como foco da promoção urbana, quando é referenciado o "cartão postal" da cidade. Um dos principais fatores aqui sustentados para justificar esta preferência pelo parque é a sua localização no bairro Jundiaí, situado próximo ao centro tra- dicional e ainda carregado de uma imagem urbana pré-concebida.

Como foi pontuado, este marketing por trás da ideia da natureza, do verde e conceitos afins, anunciados e vendidos pelos agentes imobiliários, provavelmente promove a criação da necessidade de se construir edifícios com cada vez mais pavimentos vendidos por valores exorbitantes, evidentemente voltados para "consumidores" específicos. Tal intensificação da atividade construtiva ao redor do parque, no entanto, traz consequências relativas a diversos impactos quer sejam considerados do ponto de vista ambiental como urbanos, com destaque para a degradação do curso d'água que dá origem ao Parque.

Não obstante os impactos ambientais apontados, os referentes aos novos fluxos de pessoas no bairro afetam também a paisagem social, o que nos leva a refletir sobre até que ponto determinados grupos resistirão aos efeitos da valorização destes espaços? São os detentores do capital que têm poder de escolha sobre onde investir, morar, circular e realizar atividades de lazer e entretenimento. Fazendo nova referência a Serpa, questiona-se junto ao autor: "Afinal, estamos diante de espaços verdadeiramente públicos ou de espaços concebidos e implementados para um tipo específico de público?” (Serpa, 2007, p. 39).

Por fim, tendo sanado as principais indagações do trabalho, mas criando novas questões que podem desenrolar-se em futuras pesquisas - como a questão da segregação no entorno do parque, que preocupa a população, ou ainda os impactos ambientais da verticalização intensa próximo aos cursos d'água, especialmente da nascente do Ipiranga - enfatiza-se a relevância temática de se pesquisar a imagem urbana e suas repercussões no espaço urbano. 


\section{Referências}

Alves, G. da A. A mobilidade/imobilidade na produção do espaço metropolitano. In: Carlos, A. F. A; Souza, M. L. de; Sposito, M. E. B (Orgs.). A produção do espaço urbano: agentes e processos, escalas e desafios. São Paulo: Contexto, 2013. p. 109-122.

Anônimo. Entrevista II [jan. 2020]. Entrevistadora: Ana Laura Lopes Cabral. Anápolis, GO, 2020. Gravador de dispositivo móvel (smartphone). Entrevista concedida para produção de dissertação científica.

Batista, G. S. Anápolis: 150 anos de bairrismo. Goiânia: Kelps, 2010.

Carvalho, M. M. da C.; Santana, V. L.; Morais, R. P. Áreas verdes municipais: projeto de instalação do Parque das Antas no município de Anápolis. In: Anais do I Simpósio Nacional de Ciência e Meio Ambiente: Progresso, Consumo e Natureza-Desafios ao Homem. Anápolis, 23 e 24 de set., 2010.

CE - Construtora Engecom. Residencial Rio Giom, s.d. Disponível em: <http://www.construtoraengecom.com.br/ imoveis/go/anapolis/residencial-rio-giom>. Acesso em: fev. 2019.

Corrêa, R. L. O espaço urbano. São Paulo: Ática, 3. ed., 1995.

Duarte, F. Cidade, modos de usar: um ensaio sobre Curitiba. In: Ferrara, L. D.; Duarte, F.; Caetano, K. E. (Orgs.). Curitiba: do modelo à modelagem. São Paulo: Annablume; Curitiba: Champagnat, 2007. p. 171-234.

Ferrara, L. D. O olhar periférico: Informação, Linguagem, Percepção Ambiental. São Paulo: Editora da USP, 2. ed.,1999.

Filmagens 1080P a 4K (Canal do YouTube). Entrevista $I$ [jun. 2019]. Entrevistadora: Ana Laura Lopes Cabral. Anápolis, GO, 2019. Gravador de dispositivo móvel (smartphone). Entrevista concedida para produção de dissertação científica.

Jornal Contexto. Prefeitura anuncia o parque do Ipiranga, 2010. Disponível em: <http://www.jornalcontexto.net/ prefeitura-anuncia-o-parque-do-ipiranga $>$. Acesso em: mar. 2019.

Jornal Contexto. Córrego do Parque Ipiranga pode estar em risco, alerta Prefeitura, 2014. Disponível em: $<$ http:// www.jornalcontexto.net/corrego-do-parque-ipiranga-pode-estar-em-risco-alerta-prefeitura $>$. Acesso em: mar. 2019.

LC - Lugar Certo. Apartamento com 4 quartos à venda no bairro Jundiaí, $324 \mathrm{~m}^{2}$, s.d. Disponível em: <https:// www.lugarcerto.com.br/imovel/apartamento-4-quartos-jundiai-anapolis-com-garagem-324m2-compra-e-venda-rs950000-id-341595221>. Acesso em: fev. 2019.

Moreira, J. de R. F.; Silva, C. A. da. Paisagem urbana e áreas verdes: contexto dos parques urbanos de Goiânia. Boletim Goiano de Geografia, 32(2), 239-254, 2012.

O Eco. O que é a Compensação Ambiental?, 2015. Disponível em: <https://www.oeco.org.br/dicionario-ambiental/ 28899-o-que-e-a-compensacao-ambiental/>. Acesso em: fev. 2019.

Opusic. Opus Arboreto, s.d. Disponível em: <http://opusic. com.br/imovel/opus-arboreto/>. Acesso em: fev. 2019.

Portal 6. Anápolis sela convênio para construir Jardim Botânico ao lado do Ipiranga, 2018. Disponível em: $<$ https:// portal6.com.br/2018/02/26/anapolis-recebera-r21-milhoes-do-governo-para-construir-novo-centro-administrativo1/>. Acesso em: mar. 2019.

PR - Paiva Roci. Belvedere du Parc, s.d. Disponível em: $<$ http://paivaroci.com.br/imoveis/belvedere-du-parc/ $>$. Acesso em: fev. 2019.

Prefeitura de Anápolis. Lei Orgânica do Município de Anápolis/GO. Anápolis: DOU de 06/7/2009.

Prefeitura de Anápolis. Prefeitura de Anápolis inaugura o Parque da Liberdade, 2012. Disponível em: $<$ http://anapolis.go.gov.br/portal/multimidia/noticias/ver/parque-da-liberdade-inaugurado-em-an-polis $>$. Acesso em: fev. 2019.

Prefeitura de Anápolis. Prefeitura de Anápolis promove educação ambiental com projeto Caminho das Águas, 2013. Disponível em: <http://anapolis.go.gov.br/portal/ multimidia/noticias/ver/prefeitura-de-an-polis-realiza-projeto-caminho-das-guas $>$. Acesso em: fev. 2019. 
Prefeitura de Anápolis. Lei Complementar $n^{\circ} 349$, de 07 de julho de 2016. Dispõe sobre o Plano Diretor Participativo do Município de Anápolis. Anápolis: DOU de 15/7/2016.

Prefeitura de Anápolis. Praças e outros espaços públicos são "adotados" por empresas, 2018. Disponível em: <http:// www.anapolis.go.gov.br/portal/multimidia/noticias/ver/ praasas-e-outros-espaasos-paoblicos-sapo-aadotadosa-por-empresas>. Acesso em: fev. 2019.

Rocha, H. Anápolis: e assim se passaram 100 anos. Goiânia: Kelps, 2007.

Sánchez, F. A reinvenção das cidades para um mercado mundial. São Paulo, Tese (Doutorado em Geografia) USP, 2001.
Santos, P. H. P. dos. O processo de verticalização na cidade de Anápolis entre os anos de 19997 e 2008: mudanças na paisagem do bairro Jundiaí. Anápolis, Monografia (Graduação em Geografia) - UEG, 2008.

Serpa, Â. O espaço público na cidade contemporânea. São Paulo: Contexto, 2007.

Vainer, C.; Oliveira, F. L. de.; Junior, P. de N. L. Notas metodológicas sobre a análise de grandes projetos urbanos. In: Oliveira, F. L. de; Cardoso, A. L; Costa, H. S. de M.; Vainer, C. (Orgs). Grandes projetos metropolitanos: Rio de Janeiro e Belo Horizonte. Rio de Janeiro: Letra Capital, 2012. p. 11-23. 